\title{
Analysis of Thermally Grown Oxide Developed by Thermal Barrier Coatings with the Aid of Selective Deep Etching
}

\author{
H. M. Tawancy
}

Received: 14 December 2012/Revised: 28 January 2013/Accepted: 10 February 2013/Published online: 22 February 2013

(C) Springer Science+Business Media New York and ASM International 2013

\begin{abstract}
The thermally grown oxide developed by a thermal barrier coating deposited on $\mathrm{Al}_{2} \mathrm{O}_{3}$-forming Ni-base superalloy containing $\mathrm{Hf}$ was analyzed with the aid of selective deep etching to partially expose the oxide in contact with the bond coat. Yttria-stabilized zirconia and a Ptmodified aluminide were used as top and bond coats, respectively. Thermal exposure tests were carried out at $1,150{ }^{\circ} \mathrm{C}$ in air with 24 -h cycling period to room temperature. Scanning electron microscopy combined with energy dispersive $\mathrm{x}$-ray spectroscopy and transmission electron microscopy were used to characterize the microstructure. Hafnium-rich oxide pegs enveloped by $\mathrm{Al}_{2} \mathrm{O}_{3}$ were observed to emanate from a continuous layer of $\mathrm{Al}_{2} \mathrm{O}_{3}$ and grow into the bond coat with continued thermal exposure. However, a correlation appeared to exist between the local structure and composition of the oxide and thermal stability of the bond coat. Ultimately, decohesion occurred between the continuous layer of $\mathrm{Al}_{2} \mathrm{O}_{3}$ and underlying bond coat involving fracture of the Hf-rich oxide pegs leading to spallation of the top coat.
\end{abstract}

Keywords Thermal barrier coating - Superalloy - Oxide · Electron microscopy

\section{Introduction}

Thermal barrier coatings are surface protection systems applied to gas turbine blades, which can allow the turbine

H. M. Tawancy $(\square)$

Center for Engineering Research, Research Institute,

King Fahd University of Petroleum and Minerals,

P.O. Box 1639, Dhahran 31261, Saudi Arabia

e-mail: tawancy@kfupm.edu.sa entry temperature to be increased by up to $200{ }^{\circ} \mathrm{C}$ resulting in higher engine efficiency, more power output, and less fuel consumption, e.g., [1-5]. The coating is developed by first depositing a conventional metallic coating referred to as a bond coat, e.g., a platinum aluminide or an MCrAlYtype, on the blade superalloy substrate and is then made to develop a thin layer of aluminum oxide $\left(\mathrm{Al}_{2} \mathrm{O}_{3}\right)$ about $1-2 \mu \mathrm{m}$ in thickness to act as a "glue" enhancing the adhesion of the ceramic top coat, which can be applied by either electron-beam physical vapor deposition or thermal spray technology [6]. Upon exposure at elevated temperature, the initially formed oxide layer continues to grow predominantly by inward diffusion of oxygen [7-9]. Commonly, the newly formed oxide is referred to as thermally grown oxide.

Although the exact failure mechanism of the coating system can be influenced by the processing technique [9], several studies have demonstrated that the adhesion between the thermally grown oxide and underlying bond coat plays a key role in determining the useful life of the coating [7-16]. Therefore, to develop more durable coatings, it is important to establish a better understanding of the oxidation behavior during exposure at elevated temperatures. Toward that objective, this study has been undertaken to characterize the oxidation behavior of a state-of-the-art thermal barrier coating system deposited on a nickel-based superalloy. Emphasis is placed upon the usefulness of selective deep etching in exposing the oxide surface in contact with the bond coat.

\section{Experimental Procedure}

A commercial grade of alloy MAR M 002DS ${ }^{\circledR}$ (MAR M is a registered trademark of Martin Marietta Corporation) was 
Table 1 Chemical composition of the superalloy used in the study (wt\%)

\begin{tabular}{llllllllllll}
\hline $\mathrm{Ni}$ & $\mathrm{Co}$ & $\mathrm{Cr}$ & $\mathrm{Al}$ & $\mathrm{Ti}$ & $\mathrm{Mo}$ & $\mathrm{W}$ & $\mathrm{Ta}$ & $\mathrm{Hf}$ & $\mathrm{Zr}$ & $\mathrm{Fe}$ & $\mathrm{C}$ \\
\hline 60.10 & 9.83 & 8.91 & 5.47 & 1.44 & 0.27 & 9.87 & 2.46 & 1.12 & 0.04 & 0.37 & 0.12 \\
\hline
\end{tabular}

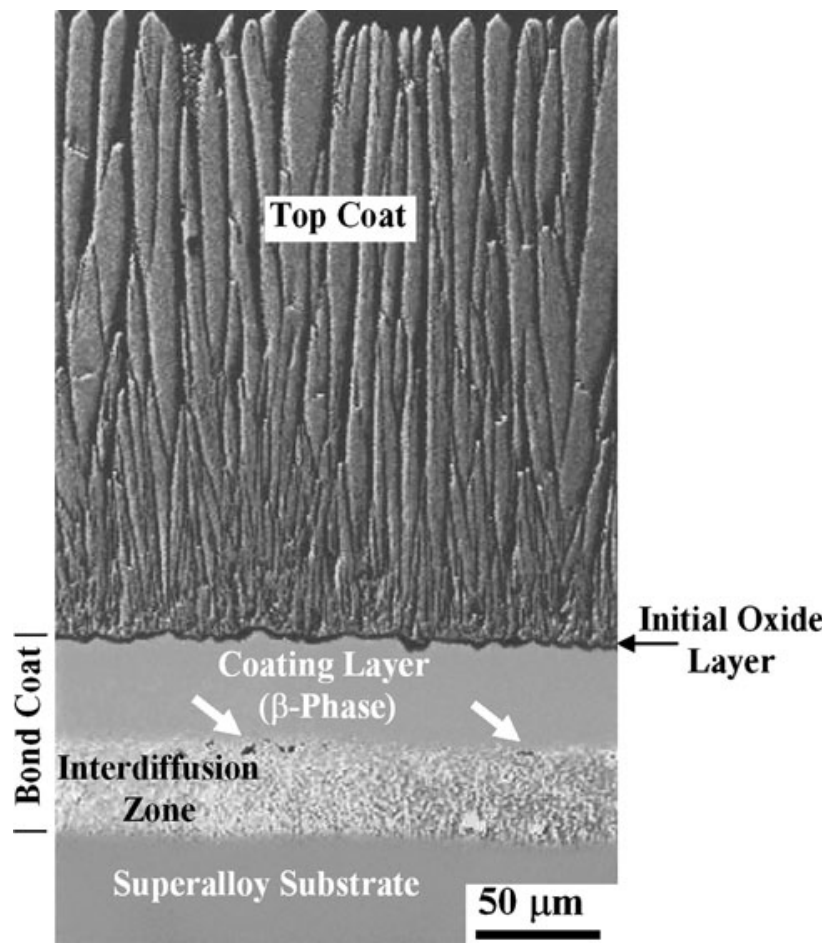

Fig. 1 Backscattered electron SEM image showing typical microstructure along a cross-section of the TBC system used in the study in the as-deposited condition (as-polished specimen). used as a substrate in this study. Table 1 shows its chemical composition as measured by inductively coupled plasma atomic energy spectroscopy with the exception of carbon, which was measured by combustion calorimetry. Samples in the form of rods about $10 \mathrm{~cm}$ in length and $8 \mathrm{~mm}$ in diameter were first grit blasted and then coated with a conventional platinum aluminide bond coat deposited by a proprietary process involving electroplating a platinum layer and an aluminizing treatment. Subsequently, the rods were given a diffusion/pre-oxidation heat treatment at $1,150{ }^{\circ} \mathrm{C}$ in air to develop the bond coat microstructure with an average thickness of about $80 \mu \mathrm{m}$ as well as a thin surface layer of $\mathrm{Al}_{2} \mathrm{O}_{3}$ about $1-2 \mu \mathrm{m}$ in thickness to enhance the adhesion of the top coat. The bond coat consists of an outer layer based upon the composition of $\beta$-NiAl followed by an interdiffusion zone. Finally, a stateof-the-art ceramic top coat consisting of yttria-stabilized zirconia (zirconia-7 wt\% yttria) with an average thickness of $250 \mu \mathrm{m}$ was deposited using the technique of electronbeam physical vapor deposition (EB-PVD) [6]. Diskshaped specimens about $8 \mathrm{~mm}$ in thickness for thermal exposure tests and microstructural characterization were machined from the coated rods. Deep etching of exposed specimens was carried out in a solution consisting of $10 \%$ bromine and $90 \%$ methanol for about $90 \mathrm{~s}$ followed by a thorough cleaning in methanol.

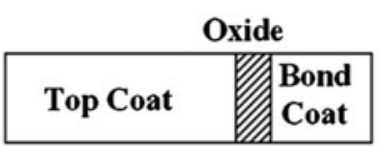

Before Etching

(a)

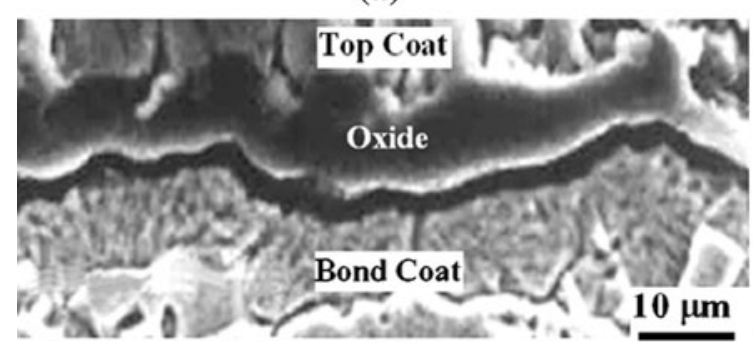

(b)

Fig. 2 An illustration of the selective deep etching technique used to expose the oxide surface in contact with the bond coat. a A schematic showing the effect of etching on the morphology of a typical metallographic specimen under $0^{\circ}$ tilt angle. b Secondary electron

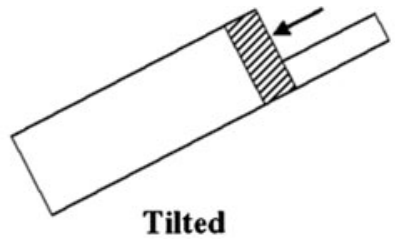

(c)

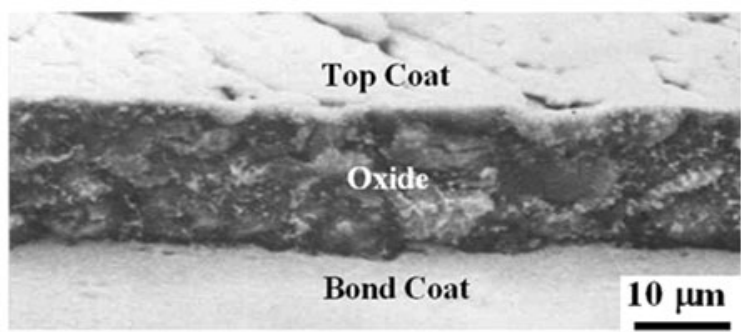

(d)

SEM image showing corresponding morphology of etched specimen (as-deposited condition). c A schematic of a specimen tilted to observe the oxide surface. d Secondary electron SEM image showing the morphology of the oxide surface as observed at $60^{\circ}$ tilt angle. 
Fig. 3 Analysis of the surface of initial oxide layer in contact with the bond coat (as-deposited condition). a Secondary electron SEM image illustrating the oxide morphology. b Energy dispersive spectrum illustrating the elemental composition of the region marked 1 in a. c Energy dispersive spectrum showing typical elemental composition of the region marked 2 in $\mathbf{a}$.
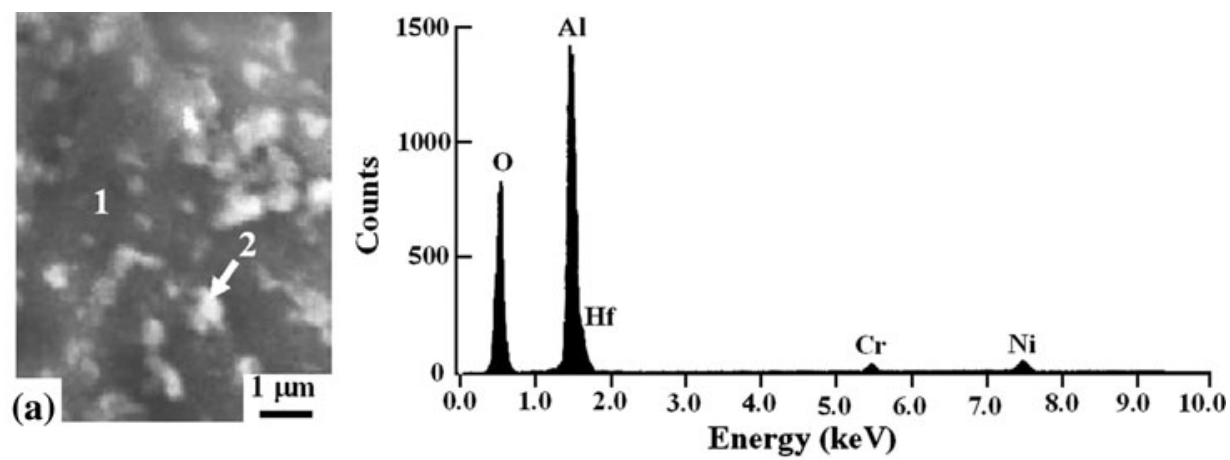

(b)

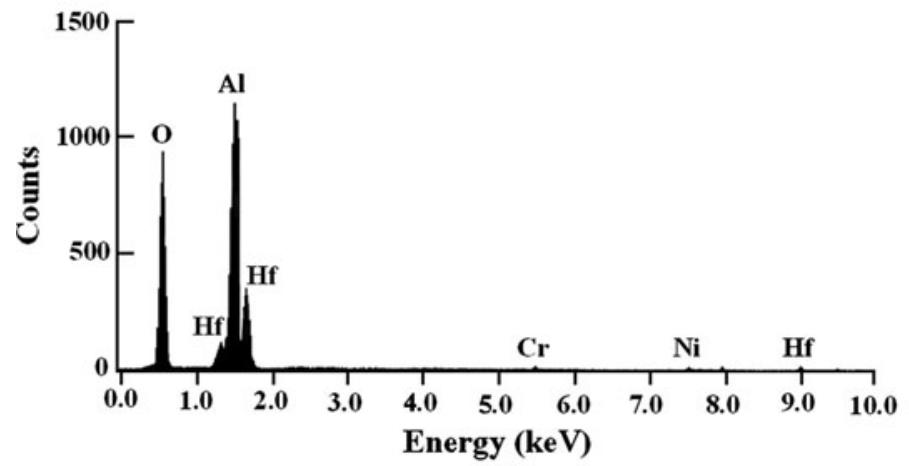

(c)

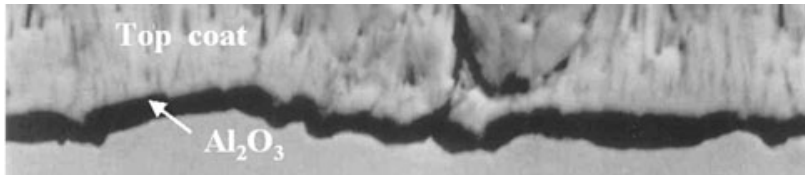

(a) Bond coat

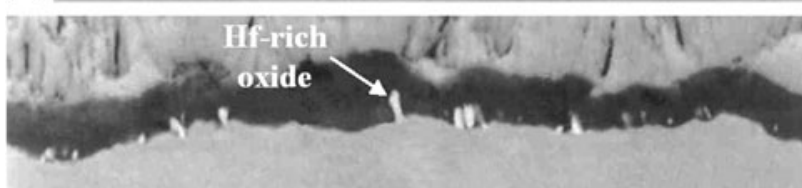

(b)
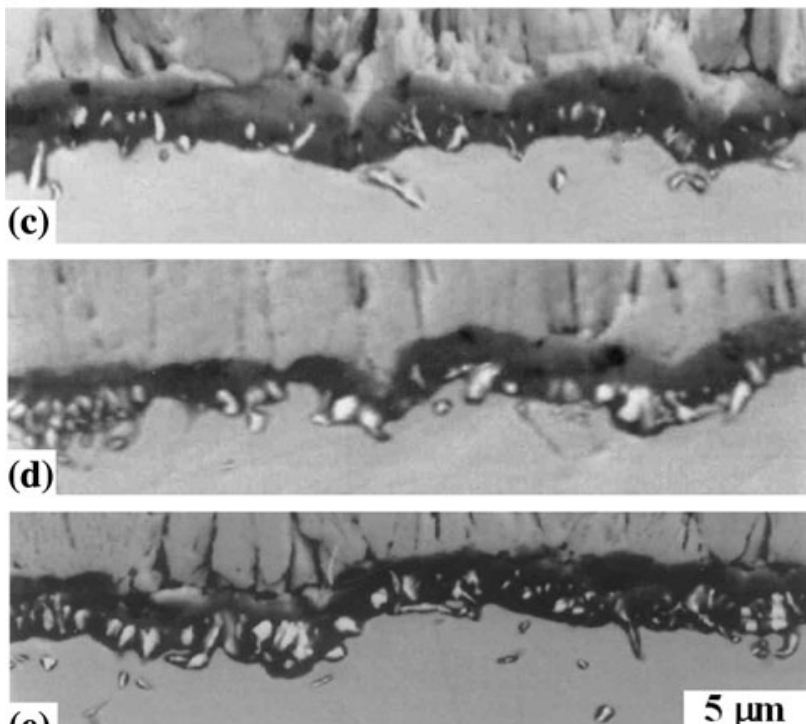

(e)
4 Fig. 4 Backscattered electron SEM images showing the effect of exposure time at $1150{ }^{\circ} \mathrm{C}$ in air with 24 -h cycling period to room temperature on the microstructure of thermally grown oxide (aspolished condition). a As-deposited condition. b 24 h. c 48 h. d $72 \mathrm{~h}$. e $96 \mathrm{~h}$.

Scanning electron microscopy (SEM) and microchemical analysis by energy dispersive $\mathrm{x}$-ray spectroscopy were used to characterize the thermally grown oxide. Specimens were examined in the etched and as-polished conditions. To observe the bond coat microstructure near the surface on the scale of transmission electron microscopy (TEM), thin foils were prepared by a combination of electropolishing and ion beam thinning [17]. Specimens were first electropolished on one side by the jet polishing technique in a solution consisting of $30 \%$ nitric acid in methanol by volume until perforation occurred. This was followed by ion beam thinning. All foils were examined at an accelerating voltage of $200 \mathrm{keV}$.

\section{Experimental Results and Discussion}

Figure 1 shows a backscattered electron SEM image illustrating a typical microstructure along a cross-section of the coating system in the as-deposited condition. Typical of top coats deposited by EB-PVD, the grain structure assumes a columnar morphology [6]. It is observed that the 


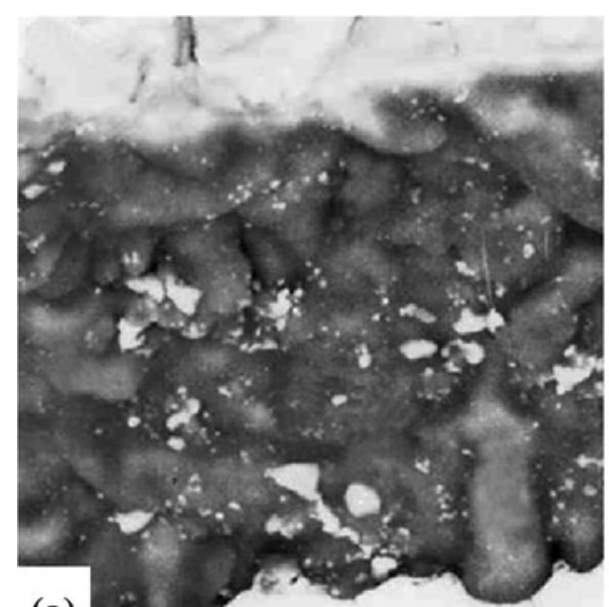

(a)

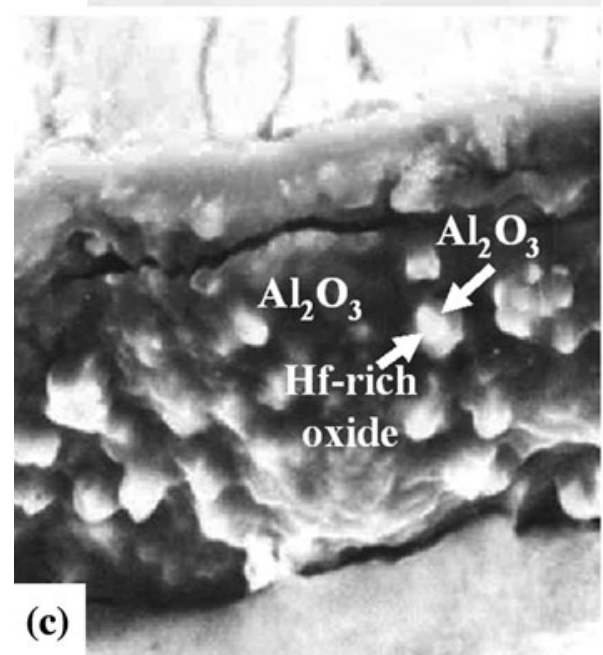

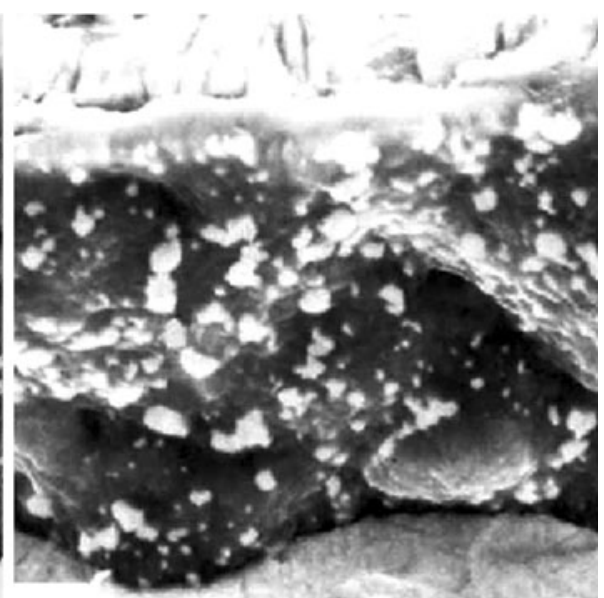

(b)

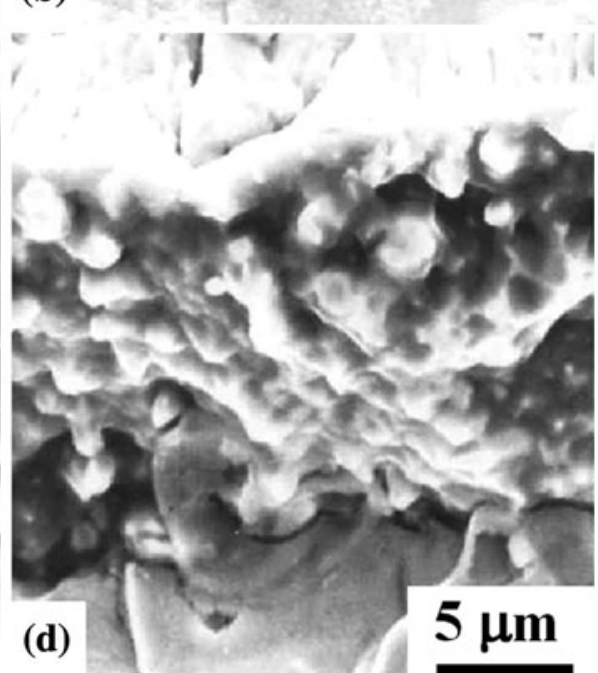

Fig. 5 Secondary electron SEM images showing the effect of exposure time at $1150{ }^{\circ} \mathrm{C}$ in air with 24 -h cycling period to room temperature on the morphology of thermally grown oxide surface in contact with the bond coat (etched condition; $60^{\circ}$ tilt angle). a 24 h. b 48 h. c 72 h. d $96 \mathrm{~h}$.

average thickness of the initial layer of $\mathrm{Al}_{2} \mathrm{O}_{3}$ separating the top coat from the bond coat is about $1.5 \mu \mathrm{m}$. As can be seen, the underlying bond coat layer of $\beta-\mathrm{NiAl}$ has a thickness of about $43 \mu \mathrm{m}$ followed by an interdiffusion zone about $35 \mu \mathrm{m}$ in thickness. Particles exhibiting dark contrast near the interface separating the two layers are alumina particles incorporated by grit blasting and mark the original superallloy surface.

An example illustrating the application of selective deep etching to expose the oxide surface in contact with the bond coat is demonstrated in Fig. 2 for a specimen in the as-deposited condition. Figure 1(a) schematically illustrates the etching technique where the bond coat is selectively dissolved to reveal the oxide surface. A secondary electron SEM image is shown in Fig. 1(b) to illustrate the morphology of an etched specimen where the electron beam is nearly parallel to the exposed oxide surface $\left(0^{\circ}\right.$ tilt angle). Figure 1(c) is a schematic of a tilted specimen to enable the observation of the exposed oxide surface. A corresponding secondary electron SEM image illustrating the respective morphology of the exposed oxide surface is shown in Fig. 1(c).

The results of analyzing the oxide surface of Fig. 1(c) are summarized in Fig. 3. It is observed from the secondary electron SEM image of Fig. 3(a) that the oxide contains a fine dispersion of second phase particles. As expected, $\mathrm{Al}$ and $\mathrm{O}$ are found to be the major elemental constituents of the oxide consistent with $\mathrm{Al}_{2} \mathrm{O}_{3}$ as shown in the spectrum of Fig. 3(b). However, it is observed that the oxide contains some $\mathrm{Hf}$ and small concentrations of $\mathrm{Cr}$ and Ni. The secondary phase particles are found to be enriched in Hf suggesting a Hf-rich oxide as demonstrated in Fig. 1(c). It is noted that the spectrum of Fig. 1(c) contains a strong $\mathrm{Al}$ peak, which could be due to the small size of the particles relative to the probe diameter exciting $\mathrm{Al}$ from the surrounding matrix. 


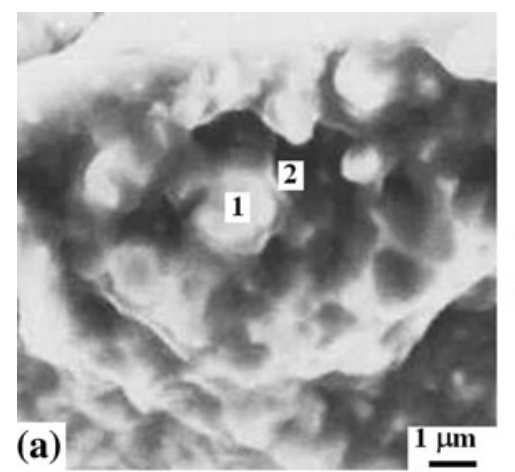

(a)

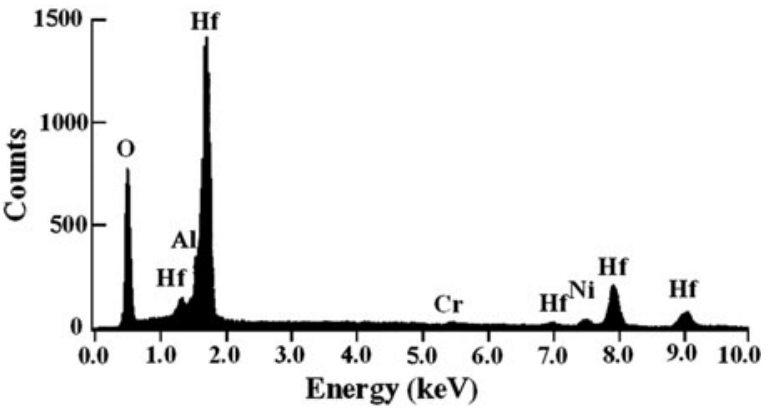

(b)

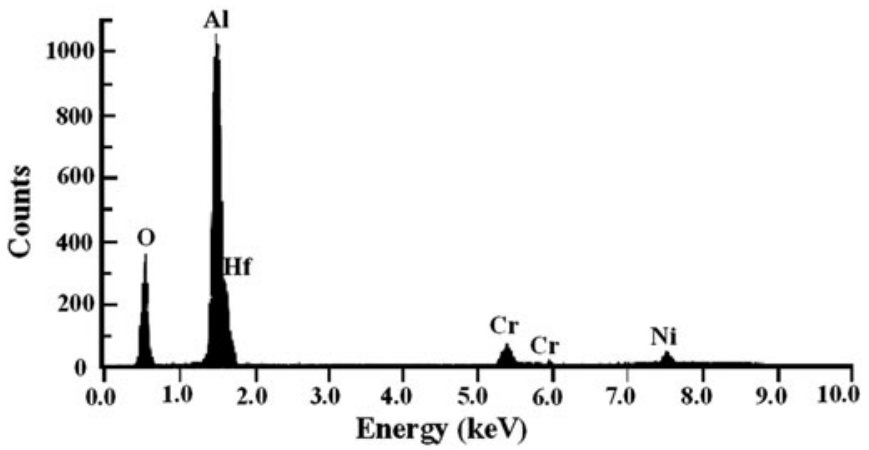

(c)

Fig. 6 An example illustrating the results of analyzing the thermally grown oxide developed after $96 \mathrm{~h}$ of exposure at $1150{ }^{\circ} \mathrm{C}$ in air with 24-h cycling period to room temperature (etched condition; $60^{\circ}$ tilt angle). a Secondary electron SEM image showing the oxide morphology as viewed at higher magnification. b Energy dispersive spectrum showing the elemental composition of the region marked 1 in a. c Energy dispersive spectrum showing the elemental composition of the region marked 2 in $\mathbf{a}$.
For comparative purposes, Fig. 4 shows backscattered electron SEM images along the coating cross-section in the as-polished condition summarizing the effect of exposure time at $1150{ }^{\circ} \mathrm{C}$ in air with 24 -h cycling period to room temperature on the microstructure of the oxide layer. As can be seen, after $96 \mathrm{~h}$ of exposure, the average oxide thickness has increased from about $1.5 \mu \mathrm{m}$ in the as-deposited condition (Fig. 4a) to $5 \mu \mathrm{m}$ after $96 \mathrm{~h}$ of exposure (Fig. 4e). Also, it is noted that the Hf-rich oxide particles observed in Fig. 3(a) can not be distinguished in Fig. 4(a), which shows the microstructure in the as-deposited condition. This could be related to the small size of the particles and their closeness to the oxide-bond coat interface in the as-deposited condition. However, as shown in Fig. 4(b) (24 h of exposure), the Hf-rich oxide particles can be distinguished and continue to grow with time and penetrate the bond coat as illustrated in Fig. 4(c-e). Also, it is noted that certain regions are more populated with Hf-rich oxide. The results presented later suggest that this behavior could be related to the tendency of the $\beta$-phase (NiAl) to transform into $\gamma^{\prime}$-phase $\left(\mathrm{Ni}_{3} \mathrm{Al}\right)$ with continued thermal exposure as a result of interdiffusion.

Figure 5 shows secondary electron SEM images illustrating the effect of exposure time on the morphology of oxide surface in contact with the bond coat of etched specimens as observed at $60^{\circ}$ tilt angle. As can be seen, Hfrich oxide pegs enveloped with $\mathrm{Al}_{2} \mathrm{O}_{3}$ emanate from a continuous layer of $\mathrm{Al}_{2} \mathrm{O}_{3}$ and continue to grow with time. This is illustrated in Fig. 6 which shows the results of analyzing the elemental composition of an oxide peg consistent with Hf-rich oxide enveloped by $\mathrm{Al}_{2} \mathrm{O}_{3}$. It is known that such oxide pegs can enhance the adhesion of $\mathrm{Al}_{2} \mathrm{O}_{3}$ to underlying metallic substrates and that the peg morphology could be related to increasing $\mathrm{Al}$ activity by reactive elements such as $\mathrm{Hf}$ promoting the formation of an envelop of $\mathrm{Al}_{2} \mathrm{O}_{3}$, e.g., [18].

An example illustrating the relationship between the structure of the thermally grown oxide and thermal stability of the bond coat is shown in Fig. 7 for specimens exposed for $72 \mathrm{~h}$ at $1150{ }^{\circ} \mathrm{C}$ in air with 24 -h cycling period to room temperature. Figure 7(a) shows a secondary electron SEM image of an etched specimen as observed at $0^{\circ}$ tilt angle. Grains of $\gamma^{\prime}$-phase are distinguished near the surface of the bond coat. A low-magnification secondary electron SEM image of the exposed oxide surface as observed at $60^{\circ}$ tilt angle is shown in Fig. 7(b) demonstrating the inhomogeneous distribution of the Hf-rich oxide. Figure 7(c) shows a 


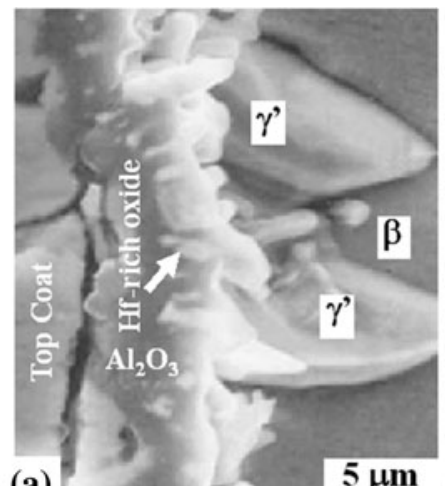

(a)

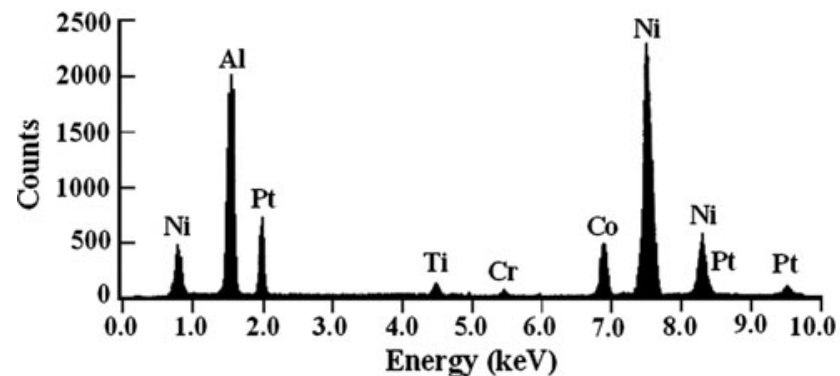

(f)

Fig. 7 An example illustrating the correlation between the structure of thermally grown oxide and thermal stability of the bond coat (specimens exposed $72 \mathrm{~h}$ at $1150{ }^{\circ} \mathrm{C}$ in air with 24-h cycling period to room temperature). a Secondary electron SEM image along a crosssection of the coating system (etched specimen; $0^{\circ}$ tilt angle). b Lowmagnification secondary electron SEM image illustrating the oxide morphology in contact with the bond coat (etched specimen; $60^{\circ}$ tilt
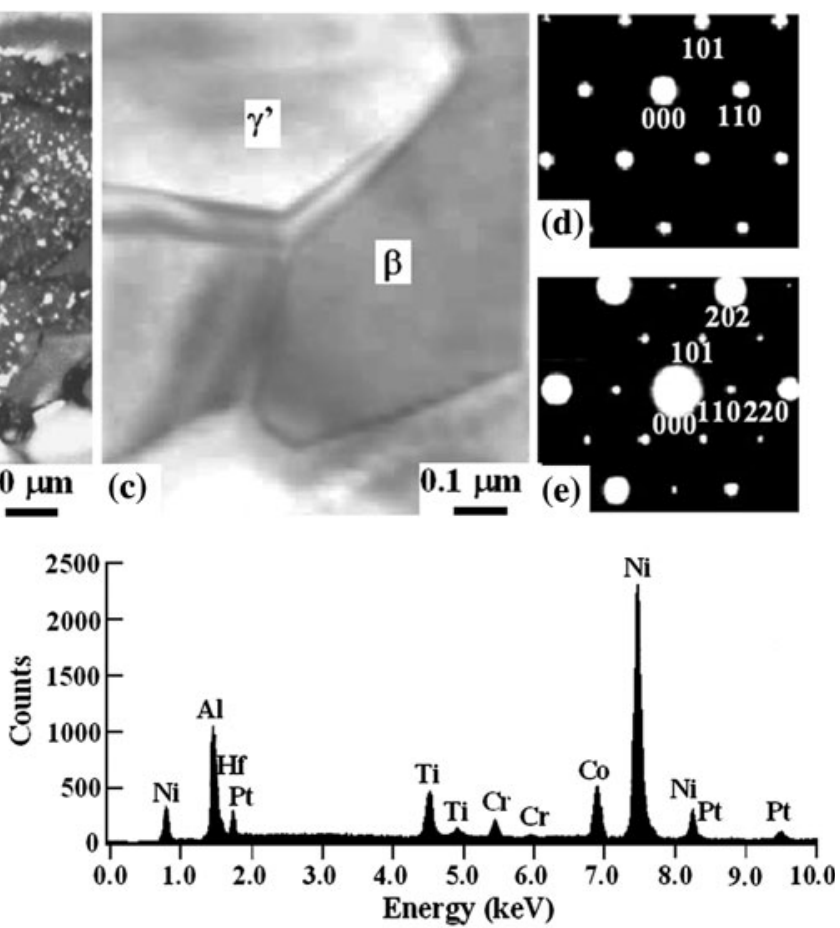

(g)

angle). $\mathbf{c}$ Bright-field TEM image showing neighboring grains of $\beta$ and $\gamma^{\prime}$-phases. $\mathbf{d}$ Microdiffraction pattern derived from the grain of $\beta$ phase in $\langle 111\rangle$ orientation. e Microdiffraction pattern derived from the $\gamma^{\prime}$-phase in $\langle 111\rangle$ orientation. f Energy dispersive spectrum illustrating the elemental composition of the $\beta$-phase. g Energy dispersive spectrum illustrating the elemental composition of the $\gamma^{\prime}$ phase.

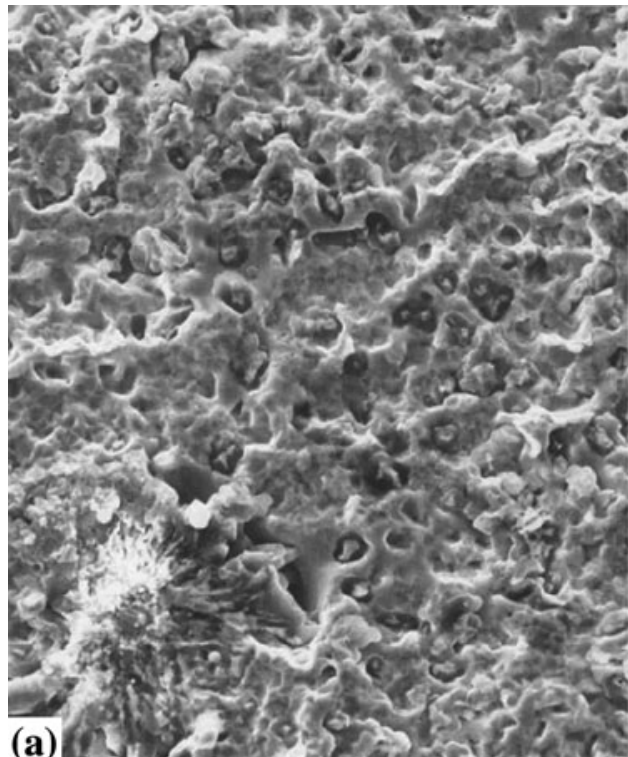

(a)

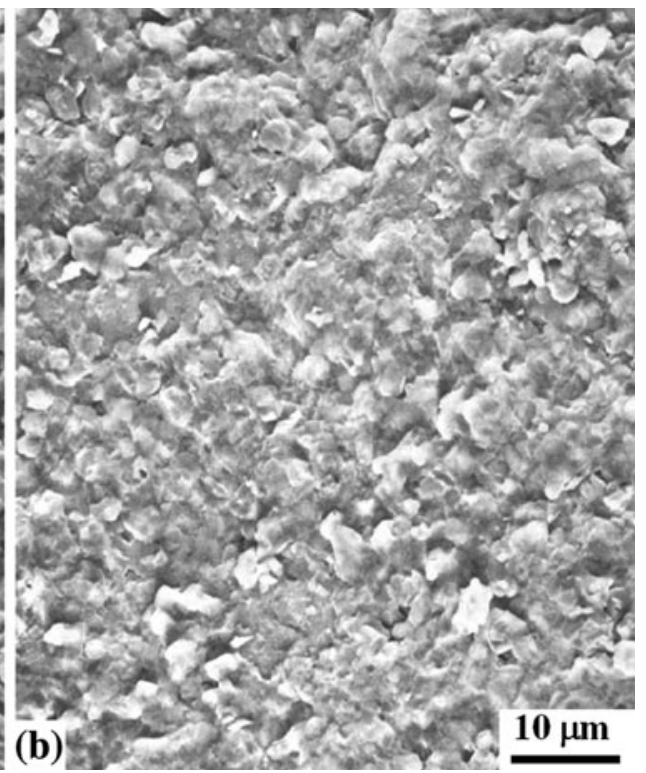

(b)

Fig. 8 Secondary electron SEM images illustrating the morphology of the surfaces exposed by failure of the coating system (192 h of exposure). a Bond coat. b Top coat. 

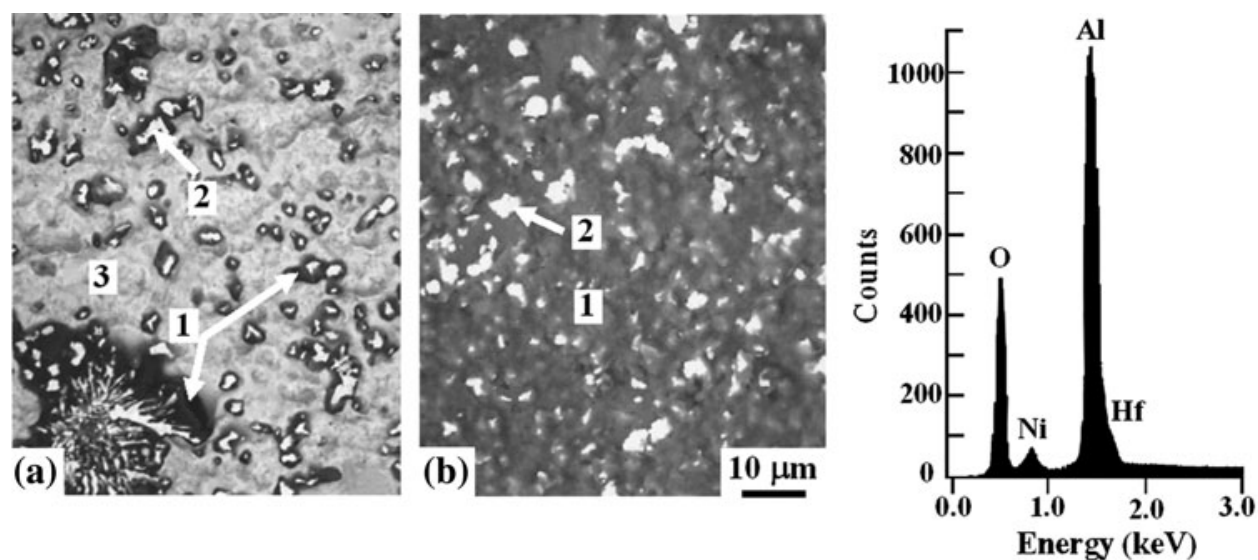

(c)

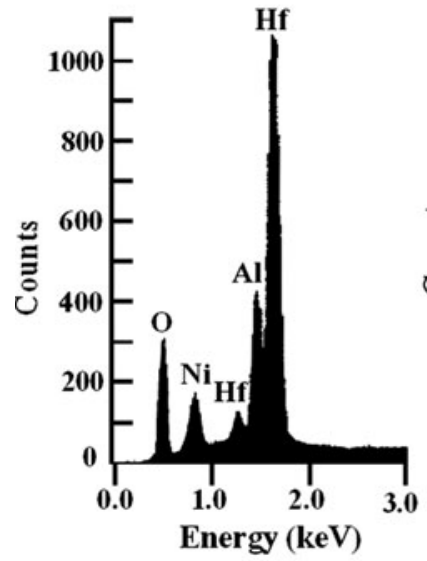

(d)

Fig. 9 Microchemical analysis of the phases present at the surfaces exposed by failure of the coating system ( $192 \mathrm{~h}$ of exposure). a Backscattered electron SEM image of the bond coat corresponding to Fig. 8(a). b Backscattered electron SEM image of the top coat

bright-field TEM image derived from a region near the bond coat surface. Corresponding microdiffraction patterns are shown in Fig. 7(d and e) consistent with those of $\langle 111\rangle_{\beta \text {-phase }}$ (cubic; B2-type superlattice) and $\langle 111\rangle_{\gamma^{\prime} \text {-phase }}$ (cubic; $\mathrm{L}_{2}$-type superlattice), respectively. In $\langle 111\rangle$ orientation, the $\beta$-phase is characterized by fundamental body-centered cubic reflections (Fig. 7d) in contrast with the $\gamma^{\prime}$-phase, which exhibits fundamental face-centered cubic reflections in addition to superlattice reflections at every $1 / 2$-position of the fundamental reflections (Fig. 7e). The tendency of the $\beta$-phase to transform into $\gamma^{\prime}$-phase is expected as a result of outward diffusion of Ni. Figure 7(f, g) shows energy dispersive $\mathrm{x}$-ray spectra illustrating the elemental compositions of the $\beta$ - and $\gamma^{\prime}$-phases, respectively. Although $\mathrm{Hf}$ is known to have a very limited solubility in the $\beta$-phase [19], it has a relatively high solubility in the $\gamma^{\prime}$-phase and acts as $\gamma^{\prime}$-stabilizer [20] consistent with the spectral data of Fig. 7(f, g). Therefore, the $\gamma^{\prime}$-phase can act as an effective sink for Hf, which may corresponding to Fig. 8(b). c Energy dispersive spectrum representative of the regions marked 1 in a and b. d Energy dispersive spectrum representative of the regions marked 2 in $\mathbf{a}$ and $\mathbf{b}$. e Energy dispersive spectrum derived from the region marked 3 in $\mathbf{a}$.

correspond to the regions with smaller density of Hf-rich oxide shown in Fig. 7(b). It is noted that an earlier study has shown that a correlation exists between the structure of thermally grown oxide and bond coat for other coating/ superalloy systems [21].

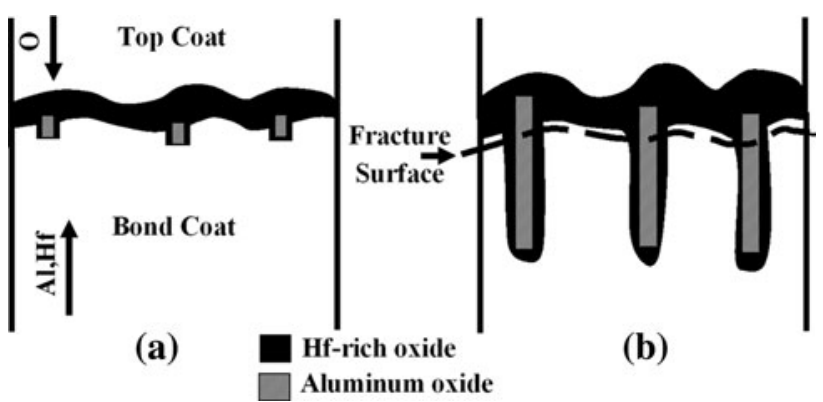

Fig. 10 A schematic illustration of the failure mode of the coating system. a Microstructure of the thermally grown oxide at a given time $t$. b Decohesion between the continuous layer of $\mathrm{Al}_{2} \mathrm{O}_{3}$ and bond coat involving fracture of the Hf-rich oxide pegs at the time of failure. 
Figure 8 shows secondary electron SEM images illustrating the morphology of the surfaces exposed by failure of the coating system after 192 h of exposure, which occurred by loss of adhesion between the thermally grown oxide and bond coat exposing the bond coat surface (Fig. 8a) and bottom surface of the top coat (Fig. 8b). Corresponding backscattered electron SEM images and elemental compositions of the phases observed at the two surfaces are shown in Fig. 9. Islands of $\mathrm{Al}_{2} \mathrm{O}_{3}$ containing $\mathrm{Hf}$-rich oxide particles are observed at the surface of the bond coat (Figs. 8a, 9a-d). The composition of the bond coat shown in Fig. 9(e) appeared to be consistent with that of $\gamma$-solid-solution phase. A continuous layer of $\mathrm{Al}_{2} \mathrm{O}_{3}$ containing particles of Hf-rich oxide is observed at the exposed surface of the top coat (Figs. 8b, 9b-d) noting that the spectra derived from the oxide phases at both surface were found to be essentially the same. Based upon the above observations, it can be concluded that failure of the coating system occurred by loss of adhesion between the continuous layer of thermally grown oxide and underlying bond coat. Observation of islands of $\mathrm{Al}_{2} \mathrm{O}_{3}$ containing particles $\mathrm{Hf}$-rich oxide at the exposed bond coat surface, and the presence of Hf-rich oxide particles dispersed within the layer of $\mathrm{Al}_{2} \mathrm{O}_{3}$ covering the corresponding bottom surface of the top coat suggests that the sequence of events leading to failure has involved fracture of the Hf-rich oxide pegs as depicted in the schematic of Fig. 10.

\section{Conclusion}

It is demonstrated that selective deep etching of metallic bond coats used in thermal barrier coatings can present a useful technique in analyzing the thermally grown oxide in contact with bond coat. Upon exposure of the coating/ superalloy system included in the study, the thermally grown oxide is found to consist of Hf-rich oxide pegs enveloped by $\mathrm{Al}_{2} \mathrm{O}_{3}$ and emanating from a continuous layer of $\mathrm{Al}_{2} \mathrm{O}_{3}$. However, a correlation is found to exist between the local density of oxide pegs and thermal stability of the bond coat. Failure of the coating system is found to occur by loss of adhesion between the continuous layer of $\mathrm{Al}_{2} \mathrm{O}_{3}$ and underlying bond coat involving fracture of the Hf-rich oxide pegs.

Acknowledgments It is a pleasure to acknowledge the continuous support of King Fahd University of Petroleum and Minerals.

\section{References}

1. B. Gleeson, Thermal barrier coatings for aeroengine applications. J. Propul. Power 22, 375-383 (2006)
2. M.J. Pomeroy, Coatings for gas turbine materials and long term stability issues. Mater. Des. 26, 223-231 (2005)

3. N.P. Padture, M. Gell, E.H. Jordan, Thermal barrier coatings for gas turbine engine applications. Science 296, 280-284 (2002)

4. C.T. Sims, Non-metallic materials for gas turbine engines: are they real? Adv. Mater. Process. 139, 32-39 (1991)

5. W.J. Brindley, R.A. Miller, Thermal barrier coatings for better engine efficiency. Adv. Mater. Process. 8, 29-34 (1989)

6. H. Laemmermann, G. Kienel, Physical vapor deposition coatings for aircraft turbine blades. Adv. Mater. Process. 140, 18-23 (1992)

7. H.M. Tawancy, L.M. Al-Hadhrami, Role of platinum in thermal barrier coatings. J. Eng. Gas Turbines Power 132, article no. 022103 (2010)

8. H.M. Tawancy, A. UI-Hamid, N.M. Abbas, M.O. Aboelfotoh, Effect of platinum on the oxide-to-metal adhesion in thermal barrier coatings. J. Mater. Sci. 43, 2978-2989 (2008)

9. A.G. Evans, D.R. Mumm, J.W. Hutchinson, G.H. Meier, F.S. Petit, Mechanisms controlling the durability of thermal barrier coatings. Prog. Mater. Sci. 46, 505-553 (2001)

10. H.M. Tawancy, L.M. Al-Hadhrami, Influence of titanium in nickel-base superalloys on the performance of thermal barrier coatings utilizing $\gamma-\gamma^{\prime}$ platinum bond coats. J. Eng. Gas Turbines Power 133, article no. 042101

11. H.E. Evans, Oxidation failure of TBC systems: an assessment of mechanisms. Surf. Coat. Technol. 206, 1512-1521 (2011)

12. B.A. Pint, K.L. More, Characterization of alumina interfaces in TBC systems. J. Mater. Sci. 44, 1676-1686 (2009)

13. C. Guerre, L. Remy, R. Molins, Alumina scale growth and degradation modes of a TBC system. Mater. High Temp. 24, 481-485 (2003)

14. N.M. Yanar, G. Kim, S. Hamano, F.S. Pettit, G.H. Meier, Microstructural characterization of the failures of thermal barrier coatings on Ni-base superalloys. Mater. High Temp. 20, 495-506 (2003)

15. D.R. Mumm, A.G. Evans, I.T. Spitsberg, Characterization of a cyclic displacement instability for a thermally grown oxide in a thermal barrier coating system. Acta Mater. 49, 2329-2340 (2001)

16. H.M. Tawancy, N. Sridhar, N.M. Abbas, D.S. Rickerby, Failure mechanism of a thermal barrier coating system on a nickel-base alloy. J. Mater. Sci. 33, 681-686 (1998)

17. P.J. Goodhew, Specimen preparation for transmission electron microscopy (Oxford University Press, Oxford, 1984)

18. A.M. Huntz, Effect of active elements on the oxidation behavior of $\mathrm{Al}_{2} \mathrm{O}_{3}$-formers, in The role of active elements in the oxidation behavior of high-temperature metals and alloys, ed. by E. Lang (Elsevier Publishing Co., Amsterdam, 1989), pp. 81-110

19. P. Tomaszewicz, G.R. Wallwork, The degradation of aluminaforming coating systems on nickel-, cobalt, and iron-based alloys by high temperature oxidation, in Reviews of high temperature materials, ed. by J. Newkirk (Freund Publishing House, London, 1982), pp. 51-60

20. E.R. Ross, C.T. Sims, Nickel-base alloys, in Superalloys II, ed. by C.T. Sims, W.C. Hagel, N.S. Stoloff (Wiley, New York, 1987), pp. 104-111

21. Y. Chen, R.C. Reed, E.A. Marquis, As-coated thermal barrier coating: structure and composition. Scr. Mater. 67, 779-782 (2012) 